\title{
Effect of Heat Input on the Structure and Properties of Aluminium Weldment TIG Welded with 4043 Filler Rod
}

\author{
Fahmida Gulshan ${ }^{1, *}$, Qumrul Ahsan ${ }^{2}$ \\ ${ }^{1}$ Materials and Metallurgical Engineering Department, Bangladesh University of Engineering and Technology, Dhaka, Bangladesh \\ ${ }^{2}$ Engineering Materials Department, Faculty of Manufacturing Engineering, University Teknikal Malaysia, Malaysia \\ *Corresponding author: fahmidagulshan@mme.buet.ac.bd
}

Copyright $(2014$ Horizon Research Publishing All rights reserved.

\begin{abstract}
A systematic investigation was made on TIG welding of aluminium alloy to improve the structureproperty relationship of weldment by controlling heat input. Aluminium plates of $1 \mathrm{xxx}$ series were welded with filler metal 4043 and with different current settings 145 A, 175 A and $195 \mathrm{~A}$. The welded samples were examined under optical and scanning electron microscopes and mechanical tests were performed to determine hardness, tensile and impact strengths. An eutectic was found to form. At the highest current setting that is at the highest heat input the eutectic mixture was coarsest and largest in size and tend to form a continuous network. On the other hand at low heat inputs the eutectic mixture did not get sufficient time to grow or to form any continuous network. The change in microstructure with heat input is also supported by the hardness, tensile and impact strength values of these plates.
\end{abstract}

Keywords Aluminium, TIG Welding, Welding Current, Eutectic

\section{Introduction}

The unique combination of light weight and relatively high strength makes aluminium the second most popular metal that is welded [1]. Al/Al alloy possesses a number of such properties as oxidation, solubility of gas and change in strength that make its welding different from the welding of steels. Aluminium or aluminium alloys are usually fusion welded with tungsten inert gas welding (TIG) process in which an inert gas $(\mathrm{Ar}, \mathrm{He})$ is supplied to reduce the oxidation of weld metal [2].

An increased use of aluminium in the automotive and ship building industry has resulted in renewed interest in the weldability of aluminium alloys. A large number of welded parts in different industries often cause premature failure due to lack of proper knowledge on weldability of aluminium alloys.

Some of the most common problems encountered in any aluminium welds and need control are porosity, cracking and filler alloy selection $[3,4]$. Ductility, fatigue strength and tensile strength of welded joints are adversely affected by the inclusion of porosity. Porosity in aluminium weld originates from entrapped gases within the weld puddle. Contaminants in the shielding gas, air, and water as well as contaminants in the base or filler metals can be the origin of these gases. During welding, partially melted zone is formed immediately outside the weld, where liquation can occur and lead to hot cracking.

In the present research, a systematic investigation was made on TIG welding of aluminium alloy to improve the structure- property relationship of weldment by controlling heat input.

\section{Experimental Procedure}

$11 \mathrm{~mm}$ thick sheets of the aluminium plates (1xxx series) were used in this study. The chemical composition was determined by optical emission spectroscopy (OES). Pieces measuring $35 \mathrm{~mm}$ in length and $16 \mathrm{~mm}$ in width were cut and the edges of each piece were prepared for TIG welding (Figure. 1).

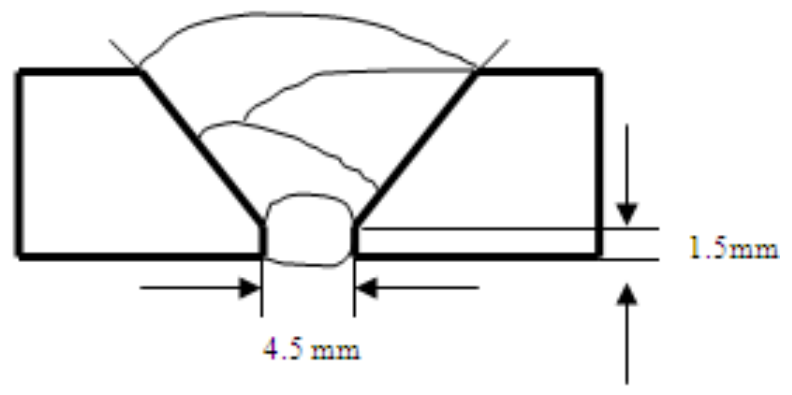

Figure 1. Joint configuration for TIG welding

The plates were rigidly clamped and welded in the flat position using 4043 filler metal and with current settings at 145A, 175A and 195A. The chemical composition of the filler metal is given in Table 1 . A $1 \%$ thoriated tungsten electrode (2.4 mm diameter) was used for welding and the welding parameters used are shown in Table 2. 
Table 1. Filler metal composition:

\begin{tabular}{|c|c|c|c|c|c|c|}
\hline $\begin{array}{c}4043 \\
5 \% \text { Silicon }\end{array}$ & Elements & $\mathrm{Si}$ & $\mathrm{Cu}$ & $\mathrm{Fe}$ & $\mathrm{Mg}$ & $\mathrm{Al}$ \\
\cline { 2 - 6 } $\begin{array}{c}\text { Aluminium } \\
\text { Welding rods }\end{array}$ & $\begin{array}{c}\text { Typical } \\
\text { tionposi }\end{array}$ & $\begin{array}{c}4.5-6 . \\
0 \%\end{array}$ & $\begin{array}{c}0.3 \\
0 \%\end{array}$ & $\begin{array}{c}0.80 \\
\%\end{array}$ & $\begin{array}{c}0.05 \\
\%\end{array}$ & $\begin{array}{c}\text { Bala } \\
\text { nce }\end{array}$ \\
\hline
\end{tabular}

Table 2. Welding parameters

\begin{tabular}{|c|c|c|c|}
\hline Material & Plate No & $\begin{array}{c}\text { Filler metal } \\
\text { used }\end{array}$ & Current used (A) \\
\hline \multirow{2}{*}{$\begin{array}{c}\text { Base metal- pure } \\
\text { aluminium } \\
\text { 1xxx series }\end{array}$} & 1 & & 145 \\
\cline { 2 - 2 } & 2 & $\begin{array}{c}4043 \\
\text { (Al-Si filler) }\end{array}$ & 175 \\
\cline { 2 - 2 } & 3 & & 195 \\
\hline
\end{tabular}

Specimens were longitudinally sectioned, prepared as per the standard metallographic practice and etched in $1 \% \mathrm{HF}$ acid in distilled water. Micrographs were recorded at weld joint, weld root, HAZ and base metal. Mechanical tests were conducted to determine the tensile, hardness and impact properties of the weld zone, HAZ and also the base metal.

Microhardness values were determined by using a knoop microhardness tester with a $100 \mathrm{gm}$ load, the load being applied for 10 seconds. Macrohardness testing was also conducted using Rockwell hardness tester with $60 \mathrm{Kg}$ load(Rockwell F).Charpy impact test specimens with $2 \mathrm{~mm}$ deep v-notch in the weld zone, in the HAZ and in the base metal were made from each weld.

All fractured surfaces were observed under a scanning electron microscope. The SEM micrographs were recorded as secondary electron images and also as backscattered images at around $10 \mathrm{KV}$. Concentrations of the various elements present were determined by energy dispersive $\mathrm{X}$-ray analysis (EDX) at $10 \mathrm{KV}$.

\section{Results and Discussion}

Chemical compositions of the base plate are shown in table 3 .

Table 3. Chemical composition of base plate

\begin{tabular}{|c|c|c|c|c|}
\hline Elements & Aluminium & Silicon & Magnesium & Iron \\
\hline $\begin{array}{c}\text { Composition } \\
\text { (Percent) }\end{array}$ & 99.1 & 0.1128 & .0018 & 0.61 \\
\hline
\end{tabular}

After welding, optical micrographs were taken at such different locations of the welded samples as at weld pool, weld root, HAZ and base metals. These micrographs are shown in Figure 2(a)-2(d).

The optical micrographs of the weld matrix of these plates showed the presence of secondary phase. The SE images of these plates (Figures 3 (a)) also revealed the presence of this secondary phase in the weld matrix. This phase was more prominent in the corresponding BSE image of the plates (Figures 4(a)). The BSE images clearly showed the compositional difference between this phase and the weld matrix. The optical micrograph (Figure 2(d)), SE image
(Figure 3(b)) and BSE image (Figure 4(b)) of base plate (pure aluminium plate) did not show any secondary phase. Thus it can be said that this secondary phase was formed during welding.

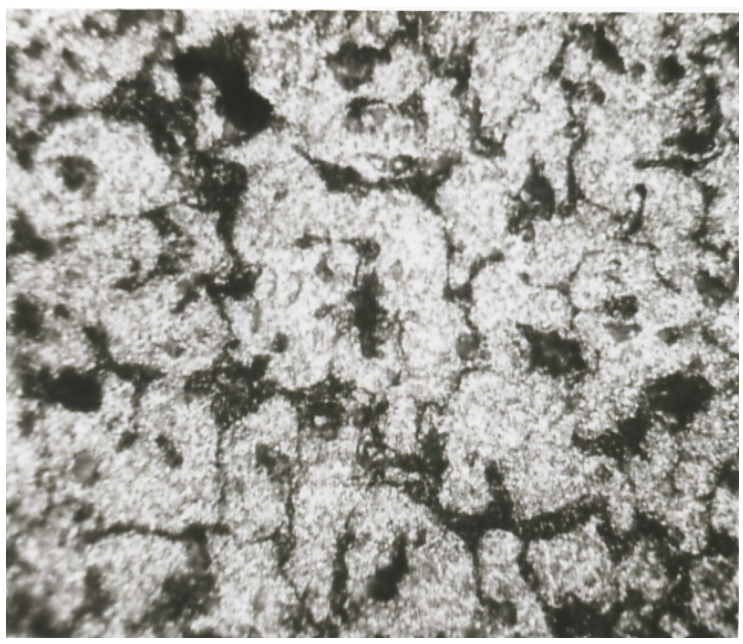

Figure 2(a). Micrograph of plate 1( weld portion)

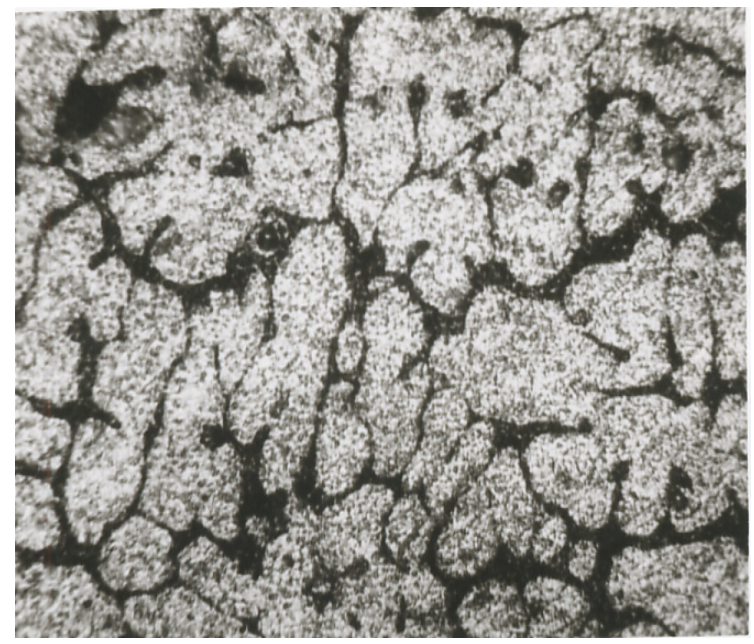

Figure 2(b). Micrograph of plate 2(weld portion)

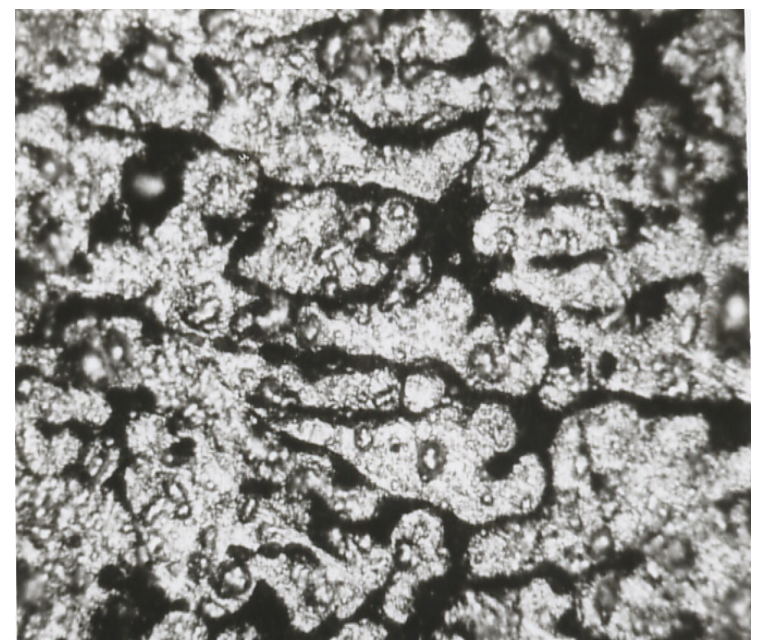

Figure 2(c). Micrograph of plate 3 (weld portion) 


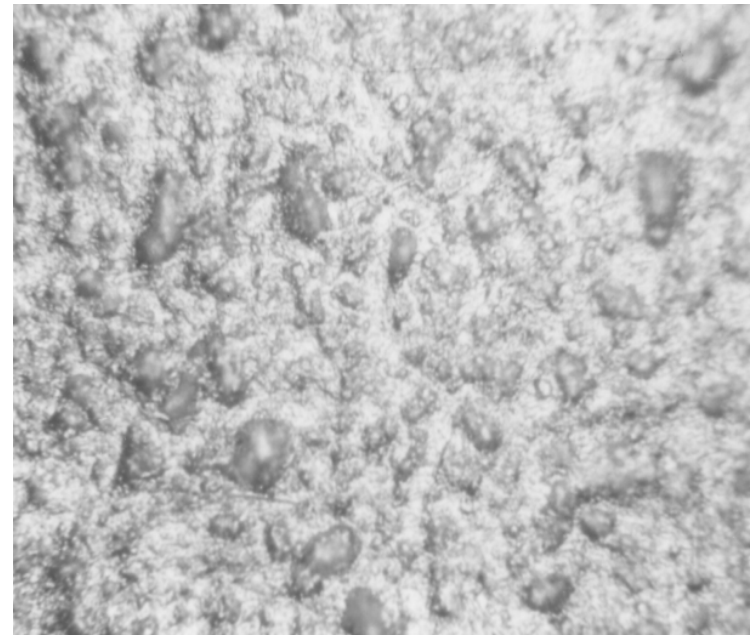

Figure 2(d). Micrograph of base plate (pure aluminium)

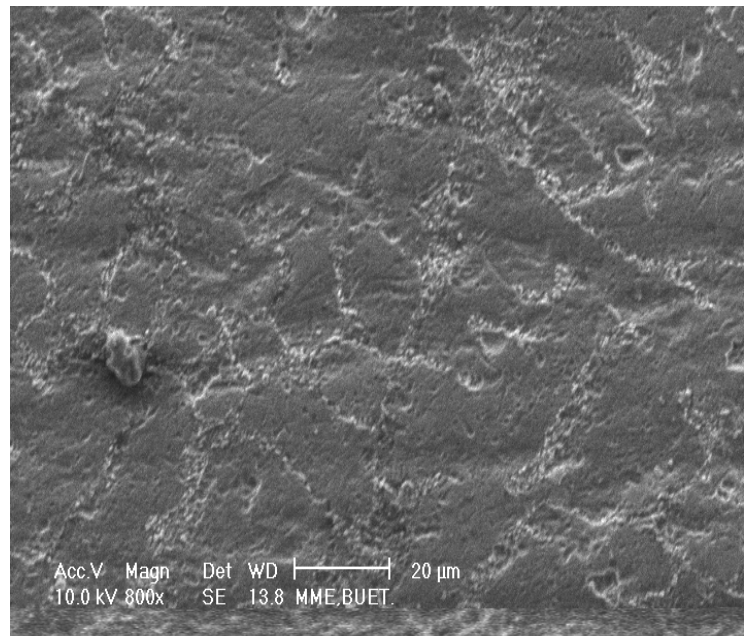

Figure 3(a). SE image of plate 1

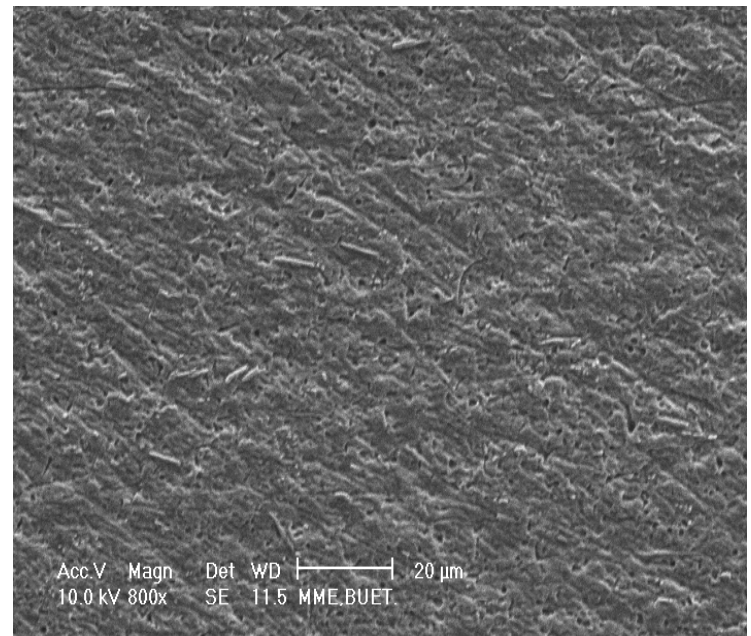

Figure 3(b). SE image of base plate Pure aluminium (1 xxx series)

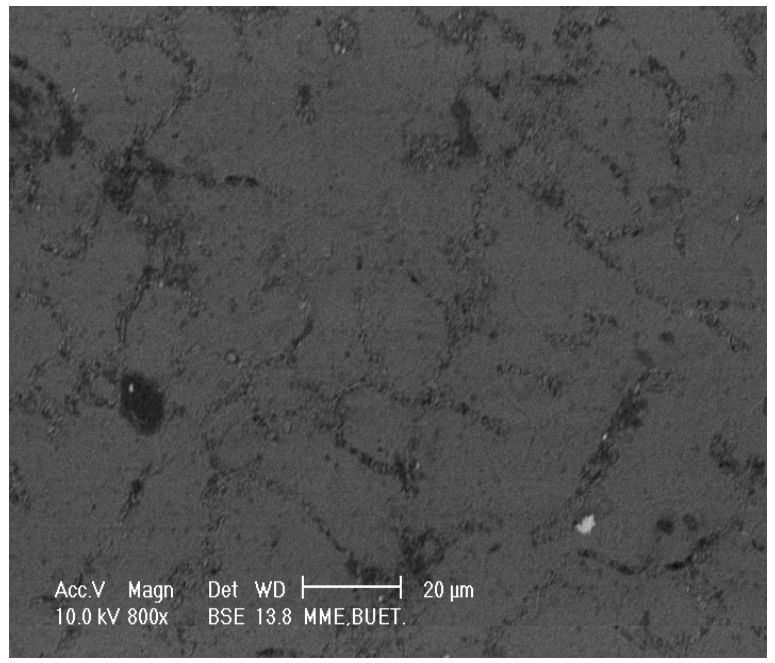

Figure 4(a). BSE image of plate 1

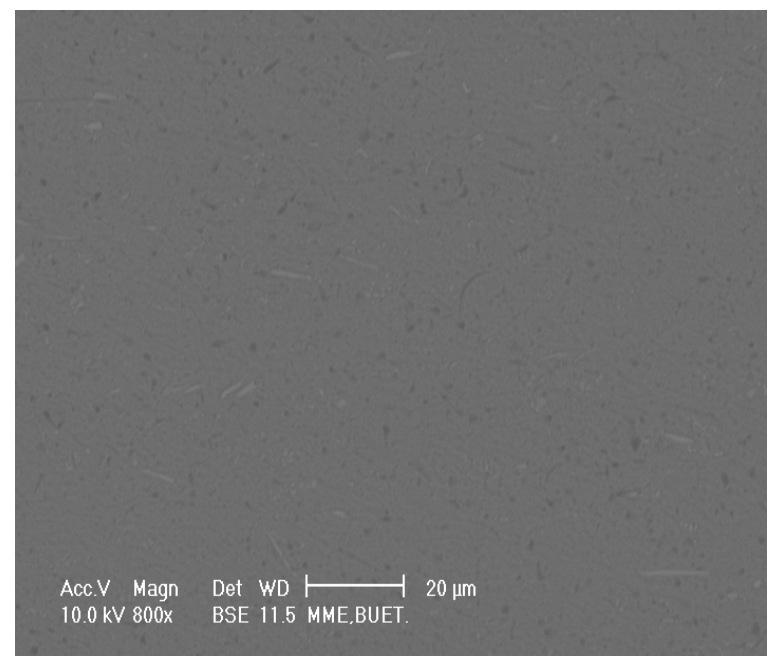

Figure 4(b). BSE image of base plate Pure aluminium (1 $\mathrm{xxx}$ series)

\subsection{Identifying the Secondary Phases}

The EDX spectra (Figure 5(a)) indicated the presence of $\mathrm{Al}$ and $\mathrm{Si}$ in the secondary phase and corresponding semi quantification analysis showed that the secondary phase consisted of 34 percent silicon. The EDX analysis of weld matrix (Figure 5(b)) indicated the presence of only 5-6 percent of Si that resembles the filler alloy composition. The binary aluminium silicon equilibrium diagram shows the formation of aluminium-silicon eutectic mixture at this condition. Thus combining the knowledge of Al-Si binary diagram and the EDX results it can be said that the secondary phase in the micrographs are Aluminium-Silicon eutectic mixture. 


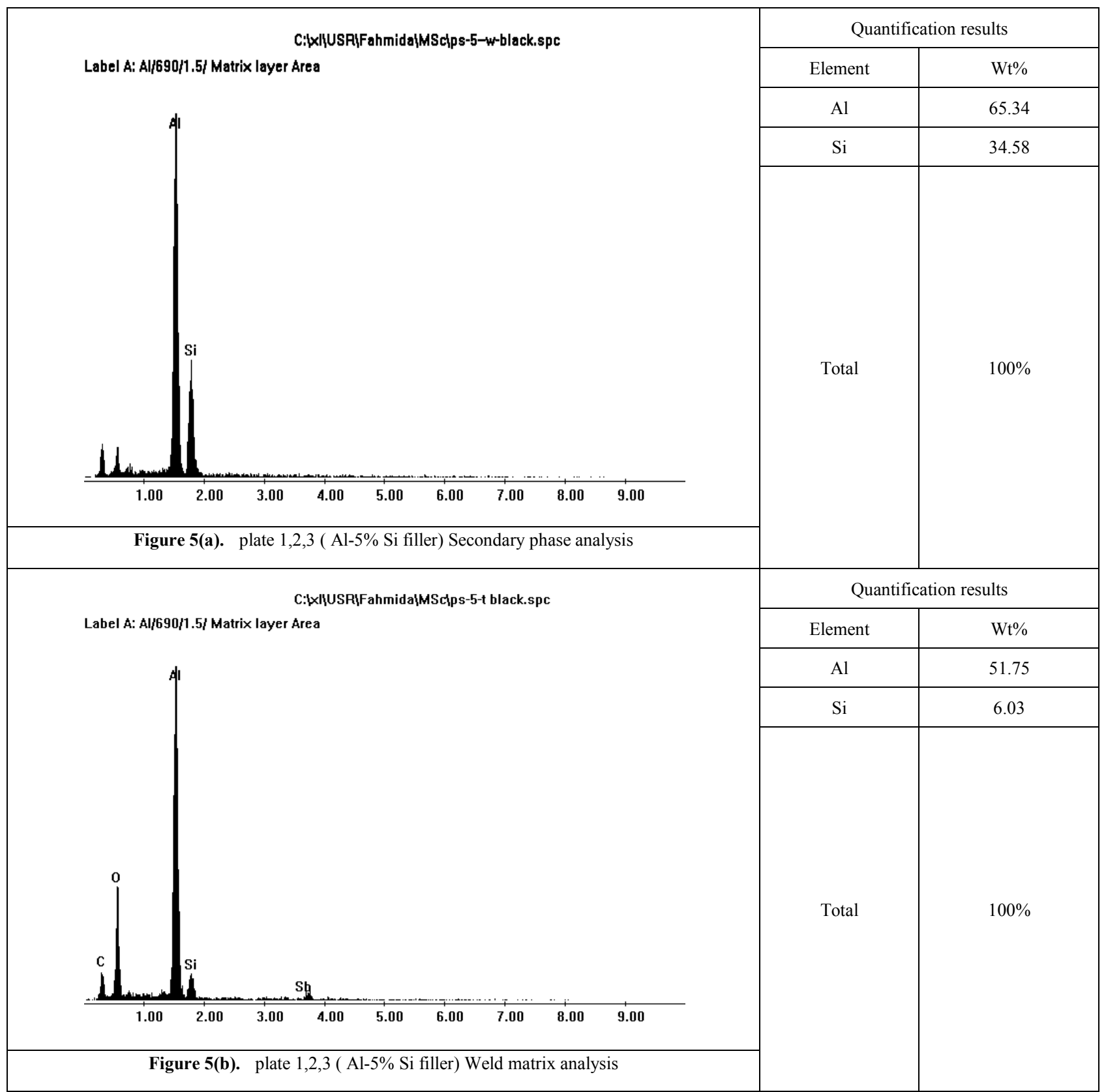

\subsection{Characteristics of the Eutectic Mixture}

The optical micrographs show that the eutectic mixture is different in distribution, shape and size in different plates. The eutectic mixture increases in size and amount with increasing current content (Figure 3(a) to 3(c)). This can be explained as follows: In plate 1 heat input was the lowest.

During solidification from the welding temperature the eutectic mixture in the weld portion in this plate did not get enough time to grow in size or to form a continuous network. But as the current content / heat input increased (plates 2 and 3 ) the Al-Si eutectic mixture got sufficient time to form and to grow in a continuous network. As a result the optical micrograph of plate 3 (welded with the highest current setting) show the most organized, large, coarser and continuous eutectic mixture than the other two plates ( 1 and $2)$. This result is in good agreement with results reported earlier[5].

It is further revealed that the shape, size and orientation of the eutectic mixture are also different at different weld location of the same plate. In the weld root area (Figure 6) the eutectic mixture is more closely spaced than that in the weld portion (Figure 2). This is because at the root, heat dissipation rate is faster than from other portion of weld. During welding root pass is performed first and during solidification heat can dissipate from all sides. So root portion seems to be quenched during solidification. But the following weld passes have slow heat dissipation rate. Because during those passes root and the base metal are already preheated that slows down the cooling rate. 


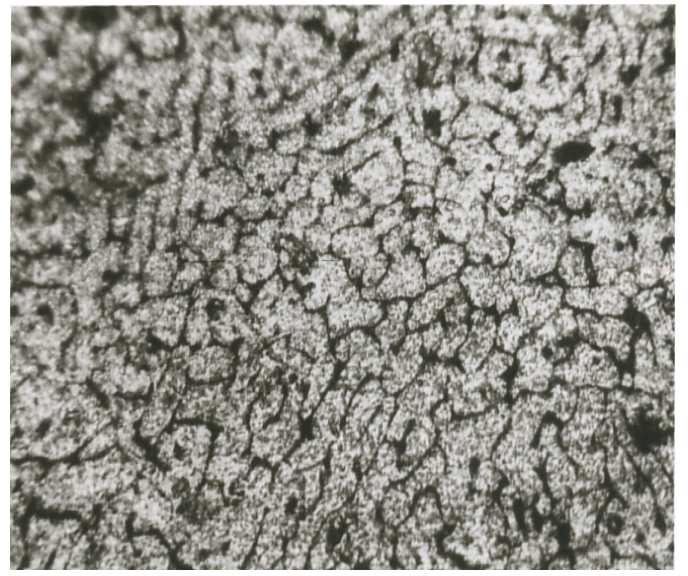

Figure 6(a). Micrograph of plate 1( Weld root )

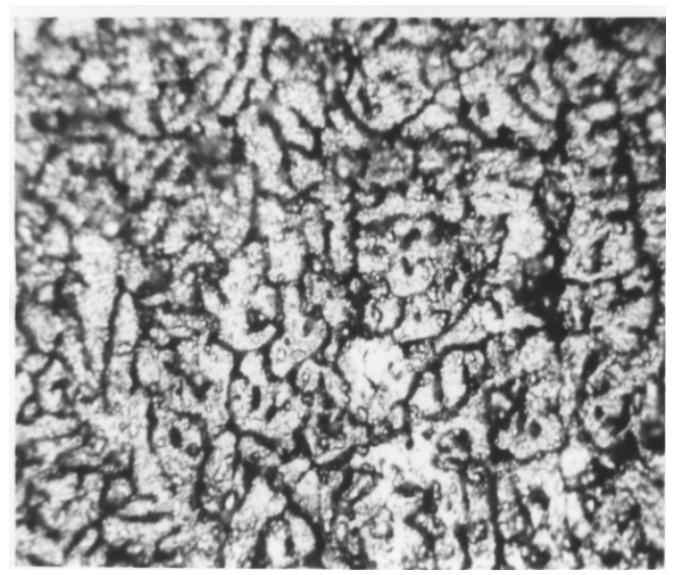

Figure 6 (b). Micrograph of plate 3(Weld root)

Discrete network structures of eutectic mixtures were observed at the heat affected zone (Figure 7) and these may be attributed to weld dilution. The optical micrographs of base plate, on the other hand showed no sign of eutectic mixture (Figure 3(d)).Similar findings were observed by Huang et al [6].For this dilution some eutectic mixture enters into the base metal which affects the fracture properties of the heat affected zone.

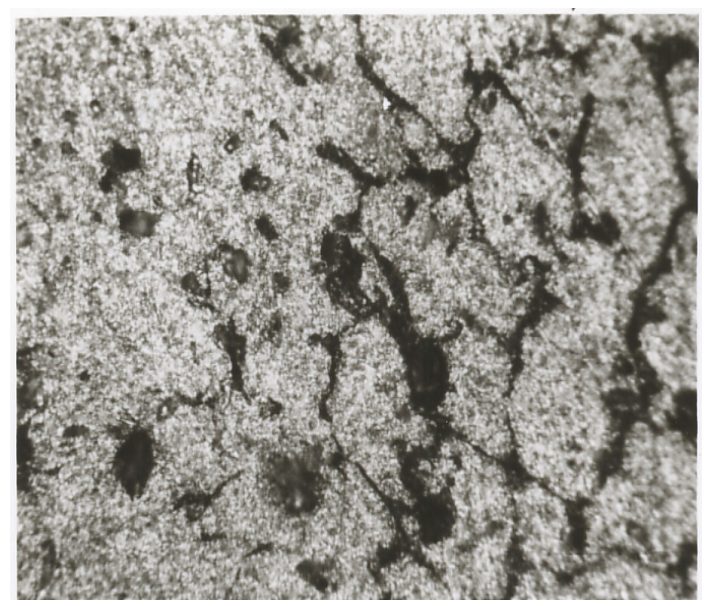

Figure 7(a). Micrograph of plate 1(HAZ)

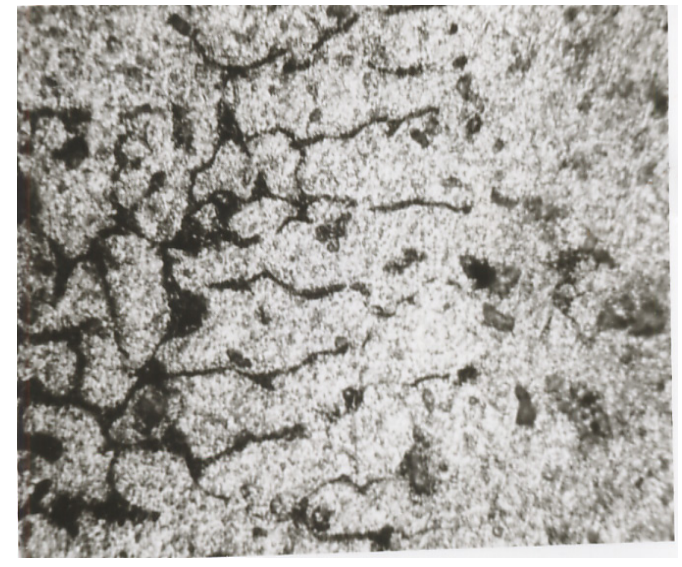

Figure 7(b). Micrograph of plate 2( HAZ)

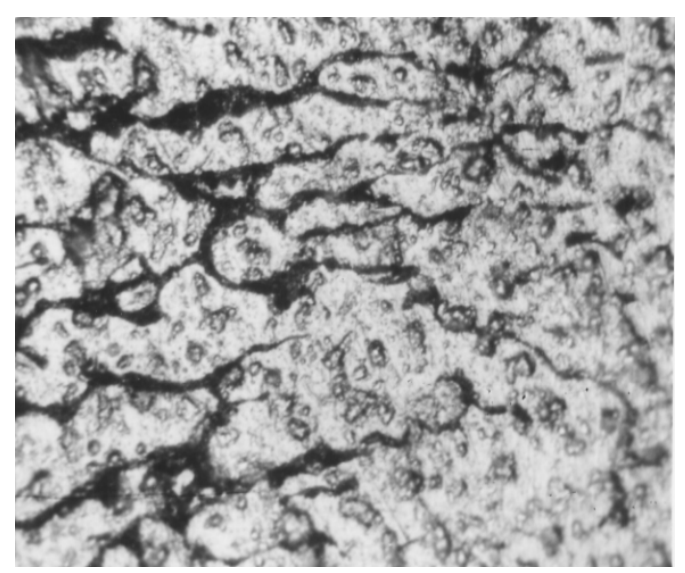

Figure 7(c). Micrograph of plate 3 ( HAZ )

\subsection{Relationship between Microstructure and Hardness Values}

The change in microstructure with heat input is also supported by the knoop microhardness profiles (Figure 8) of these plates.

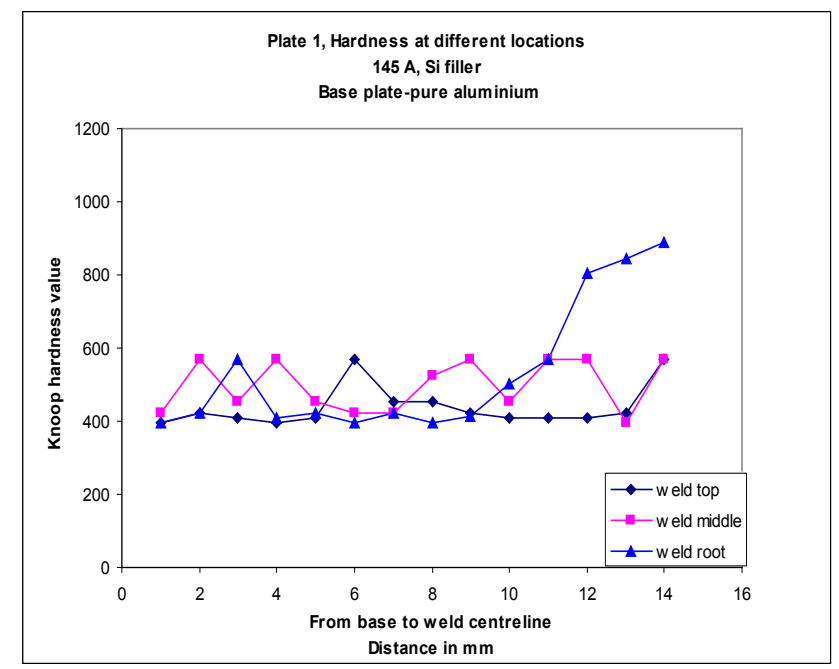

Figure 8. Comparison of microhardness values at different locations of plate 1 
This figure shows that hardness of plate 1at the weld top and middle portion are not as high as hardness of the root portion. This is because of the high heat dissipation rate of the root portion that results in smaller grains. Smaller grains show greater hardness than larger grains of weld portion.

A comparison of the hardness values of the top portions of the weld regions of the three different plates show that plates 2 and 3 have higher hardness values than that of plate 1 which was welded with the lowest current setting. It was observed previously that in plate 1 the eutectic mixture could not grow in size. This eutectic mixture is mainly responsible for the low hardness. On the other hand the eutectic mixture substantially increased in size and got coarser as the current content increased. It was the largest and coarsest in size in plate 3 .

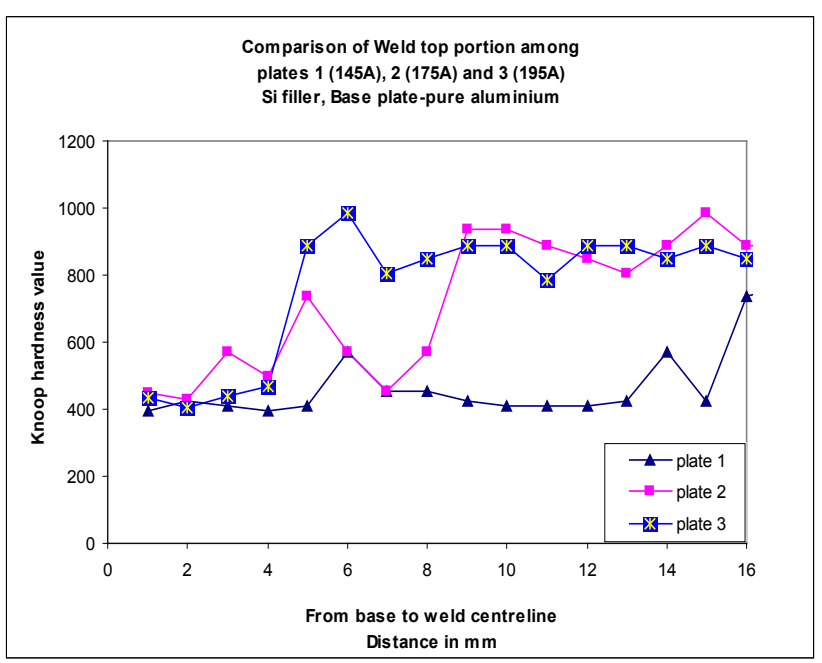

Figure 9. Comparison of microhardness values of weld top portion of plates 1,2 and 3

Table 4. Macrohardness values of plates 1,2 and 3

\begin{tabular}{|c|c|c|}
\hline \multirow{2}{*}{ Plate No } & \multicolumn{2}{|c|}{$\begin{array}{c}\text { Hardness value (Rockwell F) } \\
\text { Load }-60 \mathrm{Kg} \text {, Duration - } 15 \text { second }\end{array}$} \\
\cline { 2 - 2 } & Weld zone & Base portion \\
\hline 1 & 16 & \multirow{2}{*}{ Not enable to measure } \\
\hline 2 & 25 & \\
\hline 3 & 33 & \\
\hline
\end{tabular}

The macrohardness value of these plates (Table 1) also exhibits the same trend as the microhardness values. Plate 3 shows the highest hardness in the weld portion which is due to the largest and continuous network of $\mathrm{Al}-\mathrm{Si}$ eutectic mixture; Plates 1 and 2 have low hardness value because of the discontinuous and small eutectic mixture that did not find sufficient time to grow.

\subsection{Relationship between Fractographs and Mechanical Properties}

Impact test and tensile test results of plates 1,2 and 3 are shown in table 5.

From the results of impact and tensile tests it was found that impact energy and tensile strengths of the plates increased with increase in current content.

The fractographs of these samples are shown in Figure 10. All the fractographs show the presence of dimples from microvoid coalescence. It can be said that the microvoids initiate during plastic flow at undissolved secondary phase particles (Al-Si eutectic mixture). Separation at the site of microvoid initiation occurs across a second phase particle or at a particle-matrix interface. As the plastic strain increases, the existing microvoids grow, new microvoids are initiated and eventually the enlarged microvoids grow into close enough proximity so that the thin ridges or membranes separating them rupture and fracture occurs. The resultant fracture surfaces have numerous cuplike depressions or dimples. Dimple size appears to depend on the number of microvoid-initiation sites available and the relative plasticity of the matrix. The fracture surface of weld portion of plate 3 (welded with the highest current) shows larger microvoid dimples, because plate 3 consists of largest size of eutectic mixture and therefore a small number of initiation sites for microvoids. The fracture surface of base plate of pure aluminium with no microvoid -initiation sites exhibits no microvoid coalescence, it shows totally shear fracture. (Figure 10). On the other hand fracture surface of HAZ shows mixed mode of fracture between base and weld portion, because in the HAZ dilution causes presence of eutectic mixture there. Otherwise the HAZ would have showed the same fractured surface as that of base metal.

Table 5. Impact energy and tensile strengths of plates 1,2and 3

\begin{tabular}{|c|c|c|c|c|c|c|}
\hline \multirow{2}{*}{ Plate No } & \multirow{2}{*}{ Filler used } & \multirow{2}{*}{$\begin{array}{c}\text { Current used, } \\
\text { Ampere }\end{array}$} & \multicolumn{3}{|c|}{ Impact Energy(Joules) } & \multirow{2}{*}{$\begin{array}{c}\text { Ultimate } \\
\text { Tensile } \\
\text { strength, } \mathrm{MPa}\end{array}$} \\
\hline & & & Weld portion & $\begin{array}{c}\text { Heat Affected } \\
\text { Zone }\end{array}$ & Base & \\
\hline 1 & \multirow{3}{*}{4043} & 145 & 6 & 39 & \multirow{3}{*}{82} & 78 \\
\hline 2 & & 175 & 14 & 47 & & 89 \\
\hline 3 & & 195 & 16 & 51 & & 112 \\
\hline
\end{tabular}




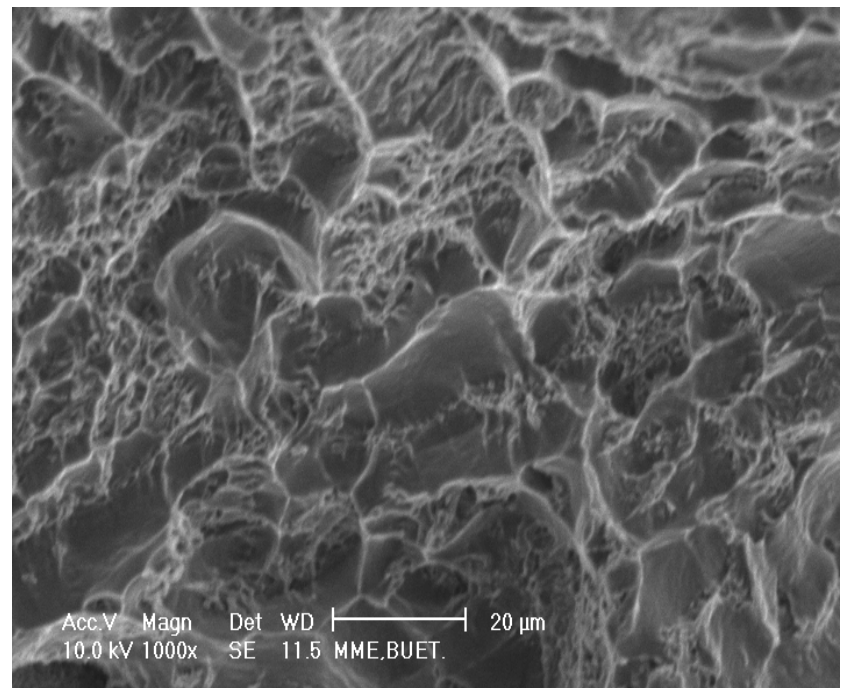

Figure 10(a). Fractograph of plate 1(weld portion)

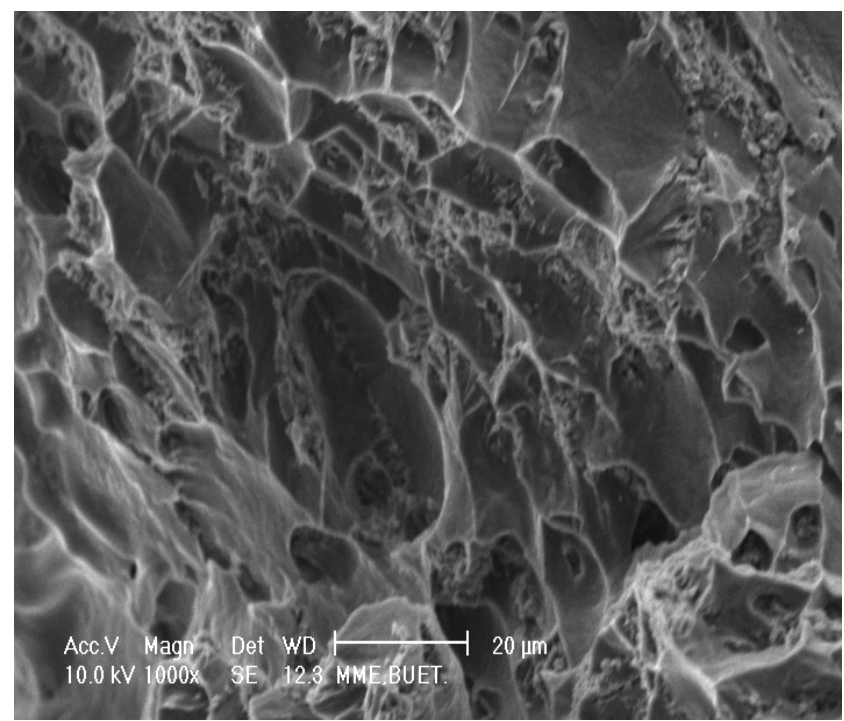

Figure 10(c). Fractograph of plate 2(weld portion)

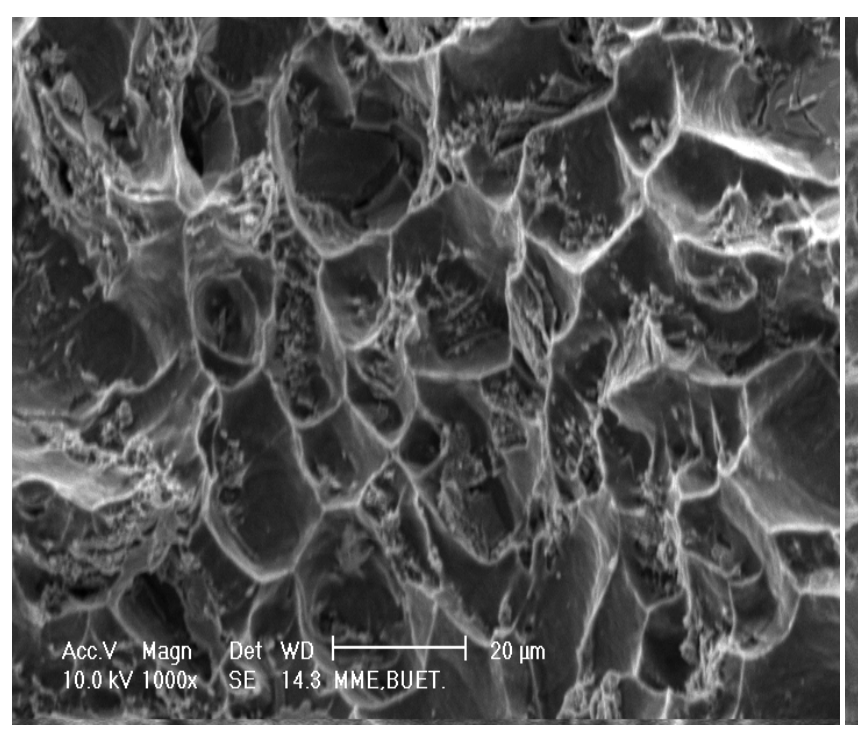

Figure10(e). Fractograph of plate 3 (notch at weld portion)

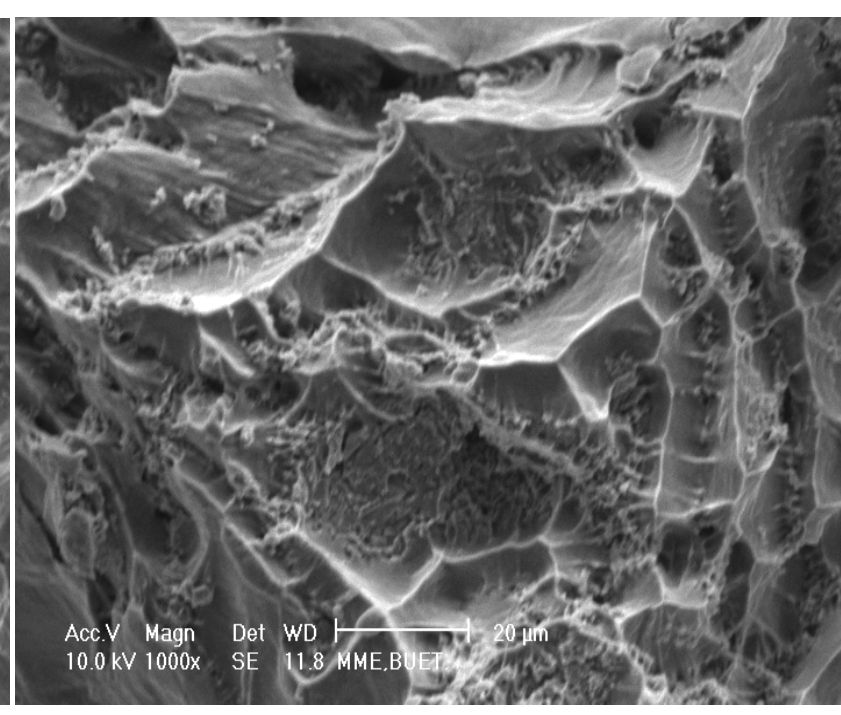

Figure 10(b). Fractograph of plate 1(HAZ)

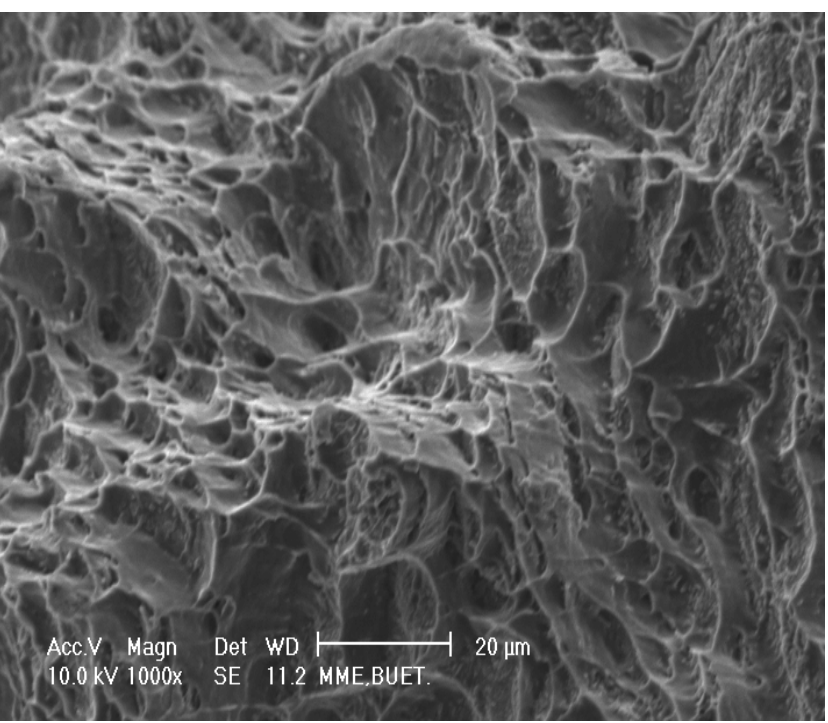

Figure 10(d). Fractograph of plate 2(HAZ)

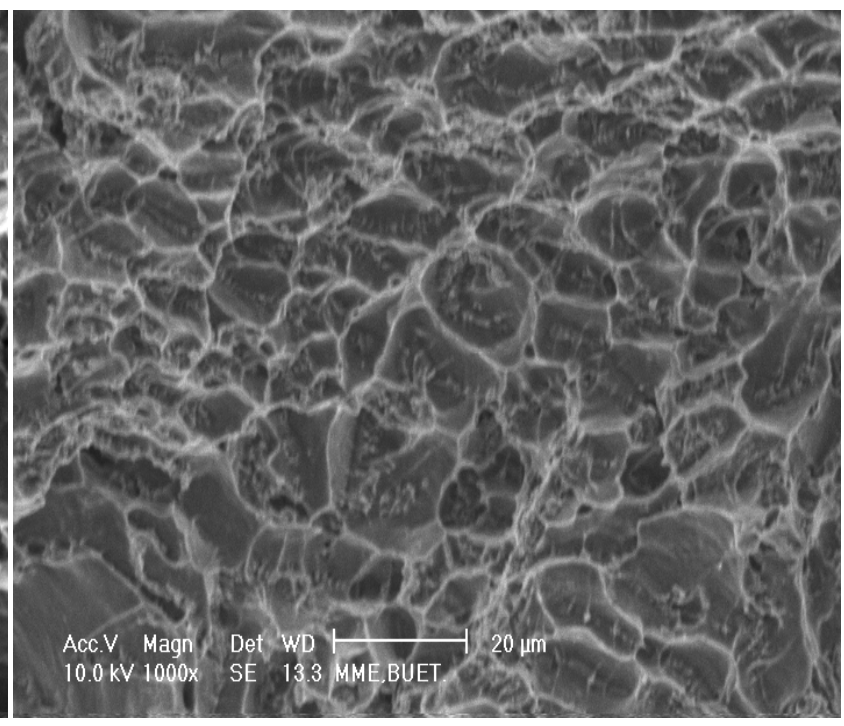

Figure 10(f). Fractograph of plate 3( notch at HAZ) 


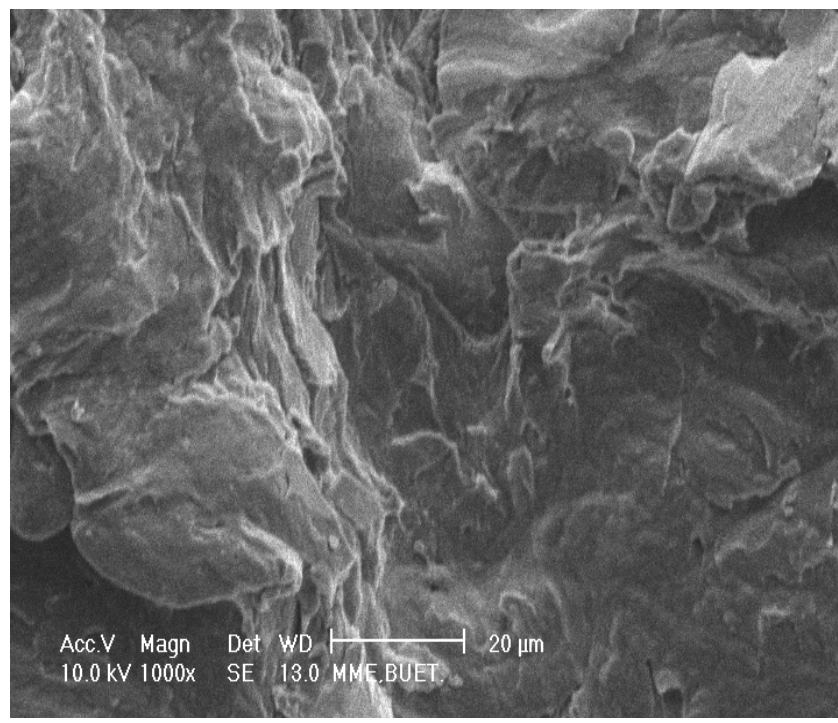

Figure 10(g). Fractograph of base plate Pure aluminium

\section{Conclusions}

From the results it can be concluded that:

During welding of pure aluminium plates with 4043 (aluminium-silicon) filler rods Al-Si eutectic mixture formed in the weld-portion and in the HAZ. Size, shape and orientation of the eutectic mixture varied with location in the weld joint and also with current settings. At the highest current setting (the highest heat input) the eutectic mixture was coarsest and largest in size and formed a continuous network. The hardness value was the highest when the eutectic mixture was coarsest and largest (at the highest current setting). High heat input created more dilution in the weld structure and higher welding current decreased the difference in hardness values at different locations of the weld. The impact energy and tensile strength improved with increase in current content.

\section{Acknowledgements}

The authors are grateful to Bangladesh University of Engineering and Technology for providing facilities to carry out this research work.

\section{REFERENCES}

[1] King,F., Aluminium and its alloys, Ellis horwood limited, England, $1^{\text {st }}$ edition, 1987, 21-128.

[2] Lancaster, J. F., "Metallurgy of welding, George allen and unwin limited", London, 3rd edition, 1980.

[3] Katoh, M., and Kerr, H. W., "Investigation of heat affected zone cracking of GTA welds of Al-Mg-Si alloys using the Varestraint test”. Welding Journal, 1987, 66(12), 360-368.

[4] Gittos, N. F., and Scott, M. H., "Heat affected zone cracking of Al-Mg-Si alloys". Welding Journal, 1981, 60(6), 95-103.

[5] Shankar, S., Riddle, Y.W., and Makhlouf, M.M. Eutectic solidification of aluminium silicon alloys, Metallurgical and Materials Transaction, 2004,35A,3038-3043

[6] Huang, C., and Kou, S., Partially melted zone in aluminium welds-planar and cellular solidification, Welding Journal, 2001, 80(2), 46-53. 